Abstracta Iranica

Revue bibliographique pour le domaine irano-aryen

Volume 40-41 | 2019

Comptes rendus des publications de 2017-2018

\title{
Carl W. Ernst. It's Not Just Academic. Essays on Sufism and Islamic Studies
}

\section{Denise Aigle}

\section{OpenEdition}

1 Journals

\section{Édition électronique}

URL : http://journals.openedition.org/abstractairanica/51621

DOI : 10.4000/abstractairanica.51621

ISBN : 1961-960X

ISSN : 1961-960X

Éditeur :

CNRS (UMR 7528 Mondes iraniens et indiens), Éditions de l'IFRI

Référence électronique

Denise Aigle, « Carl W. Ernst. It's Not Just Academic. Essays on Sufism and Islamic Studies », Abstracta Iranica [En ligne], Volume 40-41 | 2019, document 1, mis en ligne le 30 décembre 2019, consulté le 17 avril 2021. URL : http://journals.openedition.org/abstractairanica/51621 ; DOI : https://doi.org/ 10.4000/abstractairanica.51621

Ce document a été généré automatiquement le 17 avril 2021.

Tous droits réservés 


\title{
Carl W. Ernst. It's Not Just Academic. Essays on Sufism and Islamic Studies
}

\author{
Denise Aigle
}

\section{RÉFÉRENCE}

Carl W. Ernst. It's Not Just Academic. Essays on Sufism and Islamic Studies. Los Angeles: Yoda Press, 2018, ISBN 978-93-528-7

1 Cette collection de vingt-huit articles est le fruit d'une trentaine d'années de recherche effectuées par Carl Ernst entre 1984 et 2015. Il est connu pour ses travaux sur la culture indo-musulmane, dont témoigne son ouvrage, Refractions of Islam in India. Situating Sufis and Yoga, publié en 2016, ainsi que dans le champ des études sur la mystique, comme par exemple, Words of Ecstasy in Sufism, publié en 1985 et, récemment en 2018, Hallaj: Poemes of a Sufi Martyr (Voir recension P. Lory, BCAI, vol. 34, 2020 p. 192). Étant donné que ce livre regroupe des articles qui concernent des sujets très différents, tant du point de vue des thèmes abordés que des périodes historiques, It's Not Just Academic est très composite.

Les articles ont été regroupés en cinq parties. Dans la première («General and Critical Issues in Islamic Studies ", p. 3-93), certains articles concernent la manière de lire et d'étudier le Coran à l'université. Ils sont le fruit des sept années d'enseignement de l'islam de C. Ernst. Ils furent rédigés avant la publication, en 2011, de son ouvrage How to Read the Qur'an. Dans "The West and Islam» (p.38-53), il soutient que les termes "East» et "West» perpétuent le conflit colonial à travers le mythe du choc des civilisations. Il explique aussi dans ("The Global Significance of the Arabic Language », p. 80-93) comment la langue arabe a joué un rôle culturel majeur, non seulement pour les musulmans eux-mêmes, mais aussi pour les juifs, les chrétiens et beaucoup de peuples non-Arabes.

3 La deuxième partie («Early Sufism », p. 97-242) regroupe des articles sur le langage mystique et les théories soufies de l'amour mystique, notamment des soufis iraniens 
connus pour leur adhésion à l'islam extatique, tels Ḥallāj, Bāyazīd Basțāmī et Shams-i Tabrīzī. Les travaux de C. Ernst ont également marqué une nouvelle étape dans la connaissance de la doctrine et la vie de Rūzbihān Baqlì (m. 1206), avec la publication de Ruzbihan Baqli: Mysticism and the Rhetoric of Sainthood in Persian Sufism, en 1995. Dans ("Rūzbihān Baqlī on Love as "Essentiel Desire" », p. 157-164) et (" The Stage of Love in Early Persian Sufism, from Rabi'a to Ruzbihan », p. 196-216), C. Ernst, qui s'inscrit dans la lignée des travaux de Henry Corbin sur le saint homme de Chiraz, montre l'importance du thème de l'amour divin dans la doctrine et les enseignements de Rūzbihān, dont il situe la pensée par rapport aux autres maîtres extatiques.

4 La troisième partie ("Sufism, Art, and Literature », p. 245-366) est consacrée à des réflexions sur les relations entre le soufisme, la calligraphie et la poésie. Un article ("The Symbolism of Birds and Flight in the Writings of Rûzbihân », p. 261-279) étudie l'importance du symbolisme des oiseaux dans la littérature mystique et les récits visionnaires des soufis. C. Ernst considère que Rūzbihān Baqlī a été le plus productif sur le symbolisme des oiseaux. L'article ( Beauty and the Feminine Element of Spirituality », p. 296-303) concerne la beauté féminine. Selon un hadith du Prophète, Dieu est beau et il aime la beauté. Dans une autre tradition, il dit aussi : «Il y a dans le monde trois choses que je trouve belles : les femmes, le parfum et la prière » (p. 296). Le Coran lui-même parle de Joseph et Zulaykha comme « la plus belle des histoires » (12: 3). Quelle est la signification de la beauté dans la spiritualité ? Selon C. Ernst, Rūzbihān Baqlī est l'un des mystiques qui a le plus vénéré la beauté féminine, ainsi qu'en témoignent ses écrits. Deux études s'intéressent aux relations entre soufisme et calligraphie. L'article intitulé ( Sufism and the Aesthetics of Pennmanship in Sirāj alShīrāzī's Tuhfat al-Muhibbin (1454)», p. 304-323) illustre la relation entre lignage soufi et calligraphie. Le Tuhfat al-Muhibbin fut composé en 1454 dans le Deccan bahmanide par Ya'qūb b. Hasan, connu sous le nom « Sirāj al-Ḥusaynī al-Shīrāzī ». Son maître dans la capitale du Fārs fut Șadr al-Dīn Rūzbihān, un descendant à la cinquième génération de Rūzbihān Baqlī. Il vivait à l'époque du prince timouride Ibrāhīm-Sulțān, également cité par Sirāj Shīrāzī comme un des grands calligraphes de Chiraz à cette époque. Le vocabulaire et le style utilisés font appel aux concepts des écrits de Rūzbihān Baqlī. C. Ernst dit que la Tuhfat al-muhibbin est le produit du milieu calligraphique sophistiqué de Chiraz qui était un centre international pour la production des manuscrits de qualité.

5 La quatrième partie ("Contemporary Sufism», p. 369-414) comporte deux articles sur le soufisme contemporain. Enfin, dans la cinquième partie («Persianate Themes", p. 417-483), C. Ernst a regroupé trois articles sur la place de la culture persane dans les universités aux États-Unis. Il retrace l'histoire de l'enseignement de la langue et de la culture persane depuis Marshall Hodgson (m. 1968), nommé professeur à Chicago University. Dans son célèbre ouvrage, The Venture of Islam. The Classical Age, publié en 1974, il a montré l'apport fondamental de la langue et de la culture persanes dans le cadre de la formation de la culture islamique. Par la suite, Richard Frye, nommé à Harvard University en 1948, fut aussi une figure importante pour la connaissance de l'Iran. The Heritage of Persia, publié en 1962, met aussi en lumière le rôle déterminant de l'Iran dans le champ de la culture islamique, en matière de philosophie, de sciences et de soufisme. C. Ernst évoque également la figure d'autres personnalités comme par exemple Richard Bulliet, professeur à Columbia University depuis 1978, dont les ouvrages (The Patricians of Nishapur, 1972 et Conversion to Islam in Medieval Period. An Essay in Quantitive History, 1979) ont ouvert la voie à l'étude des dictionnaires biographiques comme source pour l'histoire des élites religieuses. Roy Mottahedeh a joué⿴囗十 lui aussi 
un rôle majeur pour comprendre la période bouyide et la dynamique de la cohésion sociale durant l'époque post-califale avec la publication, en 1980, de Loyalty and Leadership in Early Islamic Society. C. Ernst cite encore beaucoup d'autres importantes personnalités, mais l'absence du nom de Ehsan Yarshater (m. 2018), professeur à Columbia University et fondateur de l'Encyclopaedia Iranica, est incompréhensible étant donné le rôle majeur qu'il a joué pour le rayonnement des études iraniennes. Le dernier article ("Early Orientalist Concepts of Sufism», p. 463-483) analyse les jugements portés sur les soufis et leurs pratiques cultuelles par les premiers voyageurs européens en Iran et en Inde. François Bernier, qui a passé plus d'une décade en Inde (1658-1669), parle des superstitions, des étranges manières de se comporter et des doctrines des «Indous » (p. 465). Sir John Chardin a laissé l'un des plus célèbres récits de voyage en Perse et en Inde (1664-1670, 1672-1680). Il place les soufis au rang des mouvements religieux qui ont suscité la controverse dans les pays catholiques du XVII ${ }^{e}$ siècle. Il identifie les soufis avec les chrétiens hérétiques et dit: "It is probable that this mystical theology of the Soufies passed from the east to west by Africa ; and that is thus infected first Spain, an then the rest of Europe » (p. 469-470). C. Ernst dit que la position des voyageurs européens sur les soufis est influencée par la vison que les religieux chrétiens portaient sur l'Antiquité païenne.

6 On ne peut que se réjouir de la publication de cette collection d'articles, mais il est regrettable que la translittération des noms propres et des termes techniques ne soit pas la même d'un bout à l'autre du livre. Il existe certes un index fort utile des noms et des thèmes, mais la graphie ne correspond pas à celle que l'on trouve dans les pages référencées.

\section{AUTEURS}

\section{DENISE AIGLE}

CNRS, Orient et Méditerranée, Paris 